\title{
Breast Metachronous Carcinoma and Sarcoma in a Young Pa- tient Leading to the Diagnosis of Li-Fraumeni Syndrome
}

\section{Seidler SJ and Huber DE}

\section{Department of Gynaecology and Obstetrics Valais Hospital, Switzerland}

\section{*Corresponding author:}

\section{Seidler SJ}

Department of Gynaecology and Obstetrics

Valais Hospital,1950 Sion, Switzerland

Received : December 28, 2018

Published : January 15, 2019

\begin{abstract}
Breast cancer is the most frequently diagnosed malignancy and the leading cause of death in women, especially among women below the age of 40 years. Genetic and familial cancer syndromes are more prevalent in young patients. Through the presentation of a case report and a literature review, specific aspects of breast cancer patients with Li-Fraumeni syndrome are discussed. Our patient is a 29-year-old woman diagnosed with breast sarcoma four years after the treatment of a breast cancer by lumpectomy and radiation. Clinical presentation and familial history raised suspicion of a Li-Fraumeni syndrome, confirmed by gene sequencing. Because of a high risk of secondary malignancies, special considerations regarding breast cancer treatment options are warranted and screening for other malignancies is required.
\end{abstract}

Keywords: Li-Fraumeni Syndrome; Breast Cancer; Sarcoma; Trastuzumab

$100 \%$. Breast cancer is the most common adult malignancy among patients with LFS [4].

Throughout this case report, we aim to illustrate clinical history and special considerations once the diagnosis of Li-Fraumeni syndrome is made.

\section{Case Description}

A 25-year-old primipara patient presented in May 2015 with a high grade invasive ductal carcinoma of the left breast (cT2N1aM0). The hormonal receptors were positive, HER2/neu was amplified, and Ki- 67 was expressed in $30 \%$ of tumor cells. She underwent anthracycline-based neoadjuvant chemotherapy with Trastuzumab and subsequently breast-conserving surgery with complete axillary lymph node dissection (ypT1bN0). The patient received adjuvant breast and axillary irradiation (64Gy), postoperative Trastuzumab and hormonal therapy by Tamoxifen and LHRH agonist.

The patient's mother was diagnosed with breast cancer at age 44 . Genetic testing for BRCA1 \& 2 mutation was negative (Figure 1). 


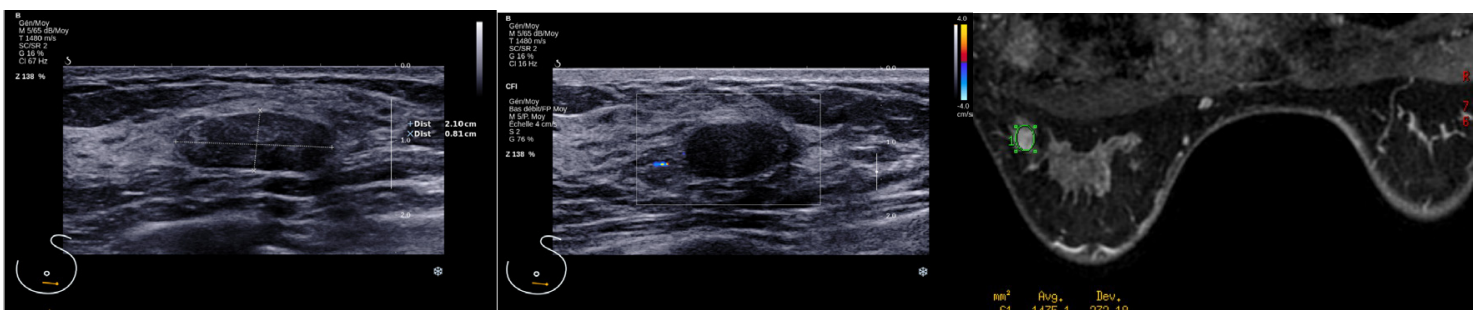

Figure 1: Ultrasound and MRI image of invasive ductal breast carcinoma (2015).

In August 2017, two years after the accomplished adjuvant treatment, the patient stopped the hormonal therapy because she wished to become pregnant. The follow-up breast imaging was unremarkable until May 2018 despite a painful surgical breast scar manifested from October 2017. Subsequently, she became pregnant without any fertility treatments. In July 2018, during the 2nd trimester of pregnancy, the patient presented with a left breast painful nodule underneath the lumpectomy scar. A color Doppler ultrasound revealed a 50 $\mathrm{mm} \times 20 \mathrm{~mm}$ mass with increased vascularization. Microbiop- sy was positive for sarcoma. The breast MRI confirmed a solid mass between the 6 th and 7 th ribs, with superficial infiltration of the costal cartilage. A total body MRI excluded a metastatic disease.

The patient underwent primary surgery, requiring 6th, 7th and 8 th rib resection and thoracic wall reconstruction using a latissimus dorsi flap combined with a Prolene mesh. Pathology confirmed a high-grade pleomorphic sarcoma completely excised, pT2, grade 2 FNCLCC (Figure 2).

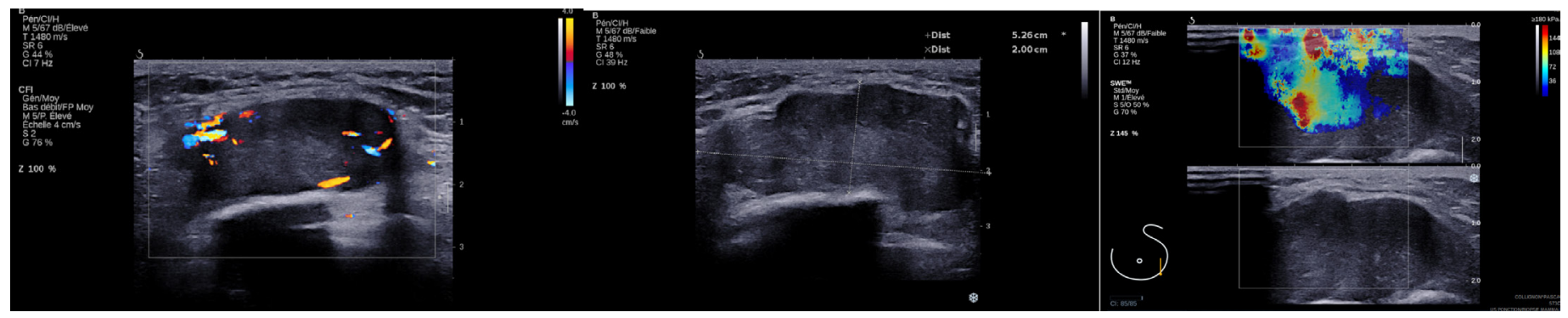

Figure 2: Ultrasound image of radiotherapy-induced breast sarcoma (2018).

Vaginal delivery was induced at 37 weeks of gestation due to ing of a 400 gene panel found a TP53 germline mutation, diagsignificant postoperative thoracic pain. The fetus was normotrophic and the placenta free of metastasis. A 2nd genetic testnostic of Li-Fraumeni syndrome. A yearly total body MRI and genetic counseling for the offspring were advised (Figure 3).

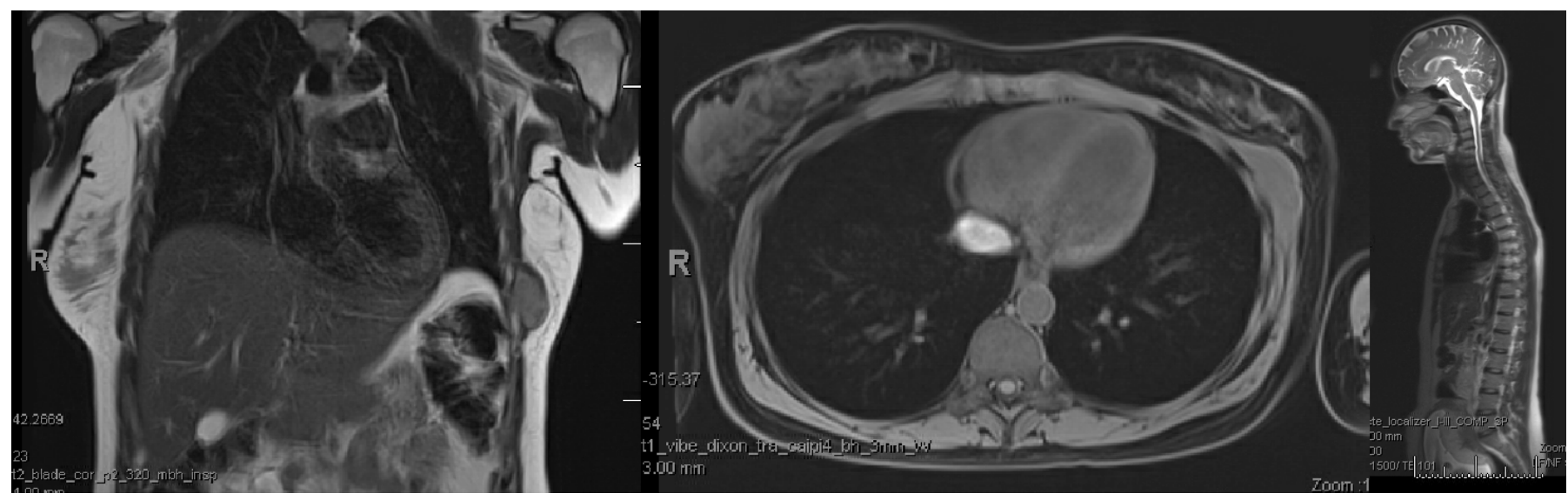

Figure 3: Thoracic MRI showing the $5 \mathrm{~cm} \times 3 \mathrm{~cm}$ mass between $6^{\text {th }}$ and $7^{\text {th }}$ ribs and total body MRI.

\section{Discussion}

Li-Fraumeni syndrome is a rare inherited autosomic dominant familial cancer syndrome characterized by TP53 tumor suppressor gene mutation. Loss of TP53 function impairs DNA re- pair and interferes with cellular apoptosis, thereby predisposing to cancers. Patients develop sarcoma, breast and adrenal gland cancers, leukemia and other various tumors at remarkably early ages. One out of two LFS females will be diagnosed with cancer before the age of 31[4].

Citation: Seidler SJ (2019). Breast Metachronous Carcinoma and Sarcoma in a Young Patient Leading to the Diagnosis of

Li-Fraumeni Syndrome. Oncogen 2(1): 4. 
The initial criteria of LFS were published in 1988 and include: sarcoma diagnosed before the age of 45 and a 1 st degree relative diagnosed with cancer before the age of 45 and a 1st or 2 nd degree relative diagnosed with cancer before the age of 45 or sarcoma at any age [5]. Afterwards, a Li-Fraumeni-like syndrome and Chompret criteria [4] were proposed in order to include patients who do not meet classical criteria, but are at risk of TP53 mutation based on the occurrence at young age of typical malignancies in the proband and their close relatives [6-8].

In a series published recently by Lee, et al. 281 out of 1060 Asian patients were diagnosed with invasive breast cancer before age 35 years. Of these, $11 \%$ and $6 \%$ were BRCA 1 and BRCA2 mutated respectively. TP53 germline mutations were found in $5 \%$ of all cases and $6 \%$ of BRCA 1 \& 2 negative patients8. This is consistent with other institutional studies that identified 3.3\% and 5.3\% TP53 mutation incidence in patients aged younger than 35 and 30 years respectively $[9,10]$.

The phenotype of breast cancer in TP53 germline mutations carriers was described in 2012 in a series by Masciari et al. In this study including 43 tumors and 39 patients, no invasive lobular carcinoma was observed. A large majority of tumors was positive for hormonal receptors and high grade. Her2/neu was overexpressed in more than $50 \%$ of tumors $[10,11]$.

In patients with breast-conserving surgery, adjuvant radiotherapy decreases the local recurrence risk and increases longterm survival [12]. Patients with positive axillary nodes and mastectomy exhibit less recurrences and mortality if ipsilateral chest wall and regional lymph nodes are irradiated, even when chemotherapy is administered $[13,14]$. Sarcomas are a well-documented. Adverse events of breast and chest wall radiation. As TP53 mutation increases susceptibility to radiation, adjuvant radiotherapy increases the risk of radiation-induced sarcomas in LFS patients [15-17].

Some studies found that $\mathrm{p} 53$ mutations are increased in recurrent breast tumors and therefore suggest that TP53 mutations drive at the resistance to chemotherapy [18].

For LFS female patients, current recommendations include breast cancer screening beginning at the age of 20-25 years by annual mammography or MRI. The cumulative breast cancer incidence is comparable to BRCA 1 \& 2 germline mutations. Risk-reducing mastectomy is therefore a valid management option $[6,8,19]$.

Besides breast cancer, screening for other malignancies is mandatory, since the risk of secondary cancers is as high as $50 \%[20]$.

\section{Conclusion}

In very young patients with breast cancer, genetic testing for TP53 mutation should be considered. The treatment options in patients with breast cancer and TP53 germline mutations (breast-conserving surgery, adjuvant radiotherapy and systemic therapies) must be carefully evaluated because of the high incidence of associated secondary malignancies. A multimodal strategy and access to a clinical trial should be offered to these patients along with systematic screening for other malignancies.

\section{References}

1. Bray F, Ferlay J, Soerjomataram I, Siegel RL, Torre LA, Jemal A (2018) Global cancer statistics 2018: GLOBOCAN estimates of incidence and mortality worldwide for 36 cancers in 185 countries. CA Cancer J Clin, 68(6): 394-424.

2. Assi HA, Khoury KE, Dbouk H, Khalil LE, Mouhieddine TH, El Saghir NS (2013) Epidemiology and prognosis of breast cancer in young women. J Thorac Dis, 5(1): S2-8.

3. Damineni S, Rao VR, Kumar S, Ravuri RR, Kagitha S, Dunna NR, et al. (2014) Germline mutations of TP53 gene in breast cancer. Tumor Biol, 35(9): 9219-27.

4. Vogel WH (2017) Li-Fraumeni syndrome. J Adv Pract Oncol, 8(7): 742-746.

5. Li FP, Fraumeni JF Jr, Mulvihill JJ, Blattner WA, Dreyfus MG, Tucker MA, et al. (1988) A cancer family syndrome in twenty-four kindreds. Cancer Res, 48(18): 5358-62.

6. Birch JM, Alston RD, McNally RJ, Evans DG, Kelsey AM, Harris M, et al. (2001) Relative frequency and morphology of cancers in carriers of germline TP53 mutations. Oncogene, 20(34): 4621-8.

7. Nandikolla AG, Venugopal S, Anampa J (2017) Breast cancer in patients with Li-Fraumeni syndrome: A case-series study and review of literature. Breast Cancer (Dove Med Press), 9: 207-215.

8. Lee DS, Yoon SY, Looi LM, Kang P, Kang IN, Sivanandan K, et al. (2012) Comparable frequency of BRCA1, BRCA2 and TP53 germline mutations in a multi-ethnic Asian cohort suggests TP53 screening should be offered together with 
BRCA1/2 screening to early-onset breast cancer patients. Breast Cancer Res, 14(2): R66.

9. Mouchawar J, Korch C, Byers T, Pitts TM, Li E, McCredie MR, et al. (2010) Population-based estimate of the contribution of TP53 mutations to subgroups of early-onset breast cancer: Australian breast cancer family study. Cancer Res, 70(12): 4795-4800.

10. Ang P, Lim IHK, Yong RYY, Lee ASG (2009) A molecular approach for identifying individuals with Li-Fraumeni syndrome who have a limited family history. Clin Genet 75(3): 294-297.

11. Masciari S, Dillon DA, Rath M, Robson M, Weitzel JN, Balmana J, et al. (2012) Breast cancer phenotype in women with TP53 germline mutations: A Li-Fraumeni syndrome consortium effort. Breast Cancer Res Treat, 133(3): 112530.

12. Clarke M, Collins R, Darby S, Davies C, Elphinstone P, Evans $V$, et al. (2005) Effects of radiotherapy and of differences in the extent of surgery for early breast cancer on local recurrence and 15-year survival: An overview of the randomised trials. Lancet 366(9503): 2087-106.

13. McGale P, Taylor C, Correa C, Cutter D, Duane F, Ewertz M et al. (2014) Effect of radiotherapy after mastectomy and axillary surgery on 10-year recurrence and 20-year breast cancer mortality: Meta-analysis of individual patient data for 8135 women in 22 randomised trials. Lancet, 383(9935): 2127-35.

14. Poortmans PM, Collette S, Kirkove C, Limbergen EV, Budach V, Struikmans H, et al. (2015) Internal mammary and medial supraclavicular irradiation in breast cancer. N Engl
J Med, 373(4): 317-27.

15. Sun S, Tremblay F, Mesurolle B (2013) Breast sarcoma after breast-conserving therapy for breast cancer in a patient with Li-Fraumeni syndrome presenting as focal nonmasslike enhancement on MRI. AJR Am J Roentgenol, 201(6): W917.

16. Duncan, M. A. \& Lautner, M. A. Sarcomas of the breast. Surg Clin North Am, 98(4): 869-876.

17. Barbosa OV, Reiriz AB, Boff RA, Oliveira WP, Rossi L (2014) Angiosarcoma in previously irradiated breast in patient with Li-Fraumeni syndrome: A case report. Sao Paulo Med J. 133(2):151-3.

18. Norberg $T$, Klaar S, Karf G, Nordgren $H$, Holmberg L, Bergh J. (2001) Increased p53 mutation frequency during tumor progression: Results from a breast cancer cohort. Cancer Res. 61(22): 8317-21.

19. Mai PL, Best AF, Peters JA, DeCastro RM, Khincha PP, Loud JT, et al. (2016) Risks of first and subsequent cancers among TP53 mutation carriers in the National Cancer Institute Li-Fraumeni syndrome cohort. Cancer, 122(23): 3673-81

20. McBride KA, Ballinger ML, Killick E, Kirk J, Tattersall MH, Eeles RA, et al. (2014) Li-Fraumeni syndrome: Cancer risk assessment and clinical management. Nat Rev Clin Oncol. 11(5): 260-71. 